\title{
Crystallization Kinetics of Metallic Glasses
}

\author{
Arun Pratap and Ashmi T. Patel \\ Condensed Matter Physics Laboratory, Applied Physics Department, \\ Faculty of Technology \& Engineering, The Maharaja Sayajirao University of Baroda, \\ Vadodara, \\ India \\ "Crystallization is still in many ways, more an art than a science." \\ -David Oxtoby, Nature, August 3, 2000.
}

\section{Introduction}

Metallic glasses are kinetically metastable materials. Metallic glass is defined as "A liquid, which has been cooled into a state of rigidity without crystallizing". Properties of metallic glasses differ form non metallic glasses. Ordinary glasses are made up of silica while metallic glasses are made of alloy metals. Ordinary glasses are transparent whereas metallic glasses are opaque. In ordinary glasses, covalent bond is observed while in metallic glasses metallic bond is observed. On the basis of internal arrangement of atoms or molecules and type of force acting between them, the material can be classified into the following two categories:

i. Crystalline solid: Those materials in which the constituent ions or atoms and molecules are arranged in regular pattern are called crystalline solids. Besides, crystalline solids have a definite external geometrical form.

e.g. Quartz, Calcite, Diamond, Sugar, and Mica

ii. Amorphous or glassy solid: Those materials do not have definite geometric pattern are called amorphous solids. In amorphous solid atoms, ions or molecules are not arranged in definite pattern.

e.g. Rubber, Glass, Plastic and Cement

Also, an amorphous solid is a solid in which there is no long range order of the positions of the atoms. Solids in which there is long-range atomic order are called crystalline solids.

At high cooling rate, any liquid can be made into an amorphous solid. Cooling reduces molecular mobility. If the cooling rate is faster, then molecules can not organize into a more thermodynamically favourable crystalline state and an amorphous solid will be formed. Materials in which such a disordered structure is produced directly from the liquid state during cooling are called "Glasses" and such amorphous metals are commonly referred to as "Metallic Glasses" or "Glassy Metals". The metallic glasses have a combination of amorphous structure and metallic bond. This combination provides a metallic glass a new and unique quality, which cannot be found in either pure metals or regular glass. 
In the past, small batches of amorphous metals have been produced through a variety of quick-cooling methods. For instance, amorphous metal wires have been produced by sputtering molten metal onto a spinning metal disk. The rapid cooling, of the order of millions of degrees a second, is too fast for crystals to form and the material is "locked in" a glassy state. Now-a-days number of alloys with critical cooling rates low enough to allow formation of amorphous structure in thick layers (over 1 millimetre) have been produced; these are known as bulk metallic glasses (BMG).

However, there are various methods in which amorphous metals can be produced, preventing the crystallization. Sputtering, glow discharge sputtering, chemical vapour deposition (CVD), gel desiccation, electrolyte deposition, reaction amorphization, pressureinduced amorphization, solid state diffusion amorphization, laser glazing, ion implantation, thin-film deposition, melt quenching and melt spinning are some of them.

The study of the thermally-activated phase transformations is of great significance in the field of materials science as the properties of materials change due to the change in the composition and/or microstructure. The properties of fully or partly crystalline materials are usually different from their amorphous counterparts. From the viewpoint of a materials scientist, the crystallization of amorphous or non-crystalline materials involves the nucleation and growth processes. The processes driven by nucleation and growth have attracted a lot of interest for tailoring technological applications. For example, the recrystallization of the deformed metals, controlling the nucleation and growth of islands on terraces in order to get large scale arrays of nanostructures in the manufacturing of thin-film transistors (Castro, 2003). Thus, the knowledge of the kinetics of crystallization would help to attain products with the required crystallized fraction and microstructure (e.g. nanocrystalline or quasicrystalline) or to avoid the degradation of materials at high processing (\& operating) temperatures.

The kinetics of the crystallization process can be studied with the help of thermo-analytical techniques namely, differential scanning calorimetry (DSC) and differential thermal analyzer (DTA). The DSC/DTA experiments can be carried out in isothermal as well as nonisothermal (linear heating) conditions (Ligero et al., 1990; Moharram et al., 2001; Rysava et al., 1987; Giridhar \& Mahadevan, 1982; Afify, 1991). Efforts made by the researchers in this field so far, to analyze the data obtained from DSC and hence to determine the kinetic parameters of the crystallization processes (say, activation energy, rate constant etc.), raise two important issues: (i) the selection of the mode of experiment (isothermal or nonisothermal) and, (ii) the choice of a sound method for the analysis of the experimental data. However, we are more concerned with the later issue due to the fact that several methods for the kinetic analysis are available in the literature. These methods are generally based on either the isokinetic hypothesis or the isoconversional principle and they can be accordingly categorized as: (1) isokinetic methods where the transformation mechanism is assumed to be the same throughout the temperature/time range of interest and, the kinetic parameters are assumed to be constant with respect to time and temperature; (2) isoconversional methods, which are generally used for non-isothermal analysis, assume that the reaction (transformation) rate at a constant extent of conversion (degree of transformation) is only a function of temperature (Lad et al, 2008; Patel \& Pratap, 2012). The kinetic parameters, in this case, are considered to be dependent on the degree of transformation at different temperature and time. The use of isoconversional methods is widespread in the physical 
chemistry for the determination of the kinetics of the thermally activated solid-state reactions. The physicochemical changes during an exothermic or endothermic event in DSC (or DTA) are complex and involve multi-step (serial or parallel) processes occurring simultaneously at different rates. Therefore, the activation energies for such processes can logically not be same and it may vary with the degree of conversion. This is contrary to the isokinetic view assuming all the constituents of the material to react simultaneously at the same rate. The activation energy, in the isokinetic case, is thus constant and independent of the degree of conversion. A strong difference of opinion persists among the researchers in the field of thermal analysis about the concept of variable activation energy (Galwey, 2003; Vyazovkin, 2003). In the metallurgical branch of materials science, most of the thermal phase transformations (like crystallization, recovery) are morphological and are considered to be governed by the nucleation and growth processes. The transformation mechanisms in these processes are also complex e.g. interface-controlled, diffusion-controlled growth. Notwithstanding this, the kinetic analysis of the transformation process like crystallization is done according to isokinetic hypothesis. The isoconversional methods are scarcely used for the study of the crystallization kinetics of metallic glasses.

\section{Theory}

To study the phase transformation, which involves nucleation and growth, many methods are developed. Most of the methods depend on the transformation rate equation given by Kolmogorov, Johnson, Mehl and Avrami (Lesz \& Szewieczek, 2005; Szewieczek \& Lesz, 2005; Szewieczek \& Lesz, 2004; Jones et al., 1986; Minic \& Adnadevic, 2008), popularly known as KJMA equation, basically derived from experiments carried out under isothermal conditions. The KJMA rate equation is given by

$$
\frac{d \alpha}{d t}=n k(1-\alpha)[-\ln (1-\alpha)]^{(n-1) / n}
$$

where, $a \rightarrow$ degree of transformation at a given time $t$,

$n \rightarrow$ Avrami (growth) exponent

$k \rightarrow$ the rate constant

The Arrhenius form of the rate constant is given by

$$
k(T)=k_{0} \exp \left(-\frac{E}{R T}\right)
$$

where, $k_{0} \rightarrow$ pre-exponential factor

$\mathrm{E} \rightarrow$ activation energy, and

$\mathrm{R} \rightarrow$ universal gas constant

KJMA rate equation is based on some important assumptions and it has been suggested that the KJMA kinetic equation is accurate for reactions with linear growth subject to several conditions (Minic et al., 2009).

The isoconversional methods are also known as model-free methods. Therefore, the kinetic analysis using these methods is more deterministic and gives reliable values of activation energy E, which depends on degree of transformation, $a$. However, only activation energy 
will not give a perfect picture of crystallization kinetics. The microstructural information (e.g. dimensionality of the growth) of the precipitating phase during the transformation is also very important for understanding the whole kinetics of crystallization. Microstructural information would be known to us when we take the isokinetic methods into account. Therefore, the complementary use of both the methods is more useful for understanding the kinetics of crystallization.

Differential Scanning Calorimetry (DSC) has become a convenient and widely used tool for studying the kinetics of phase transformations. The volume fraction $(x)$ of the sample transformed in crystalline phase during the crystallization event has been obtained from the DSC curve as a function of temperature $(T)$. The volume fraction of precipitated crystal can be obtained from the DSC curve by using

$$
x=s / s_{0}
$$

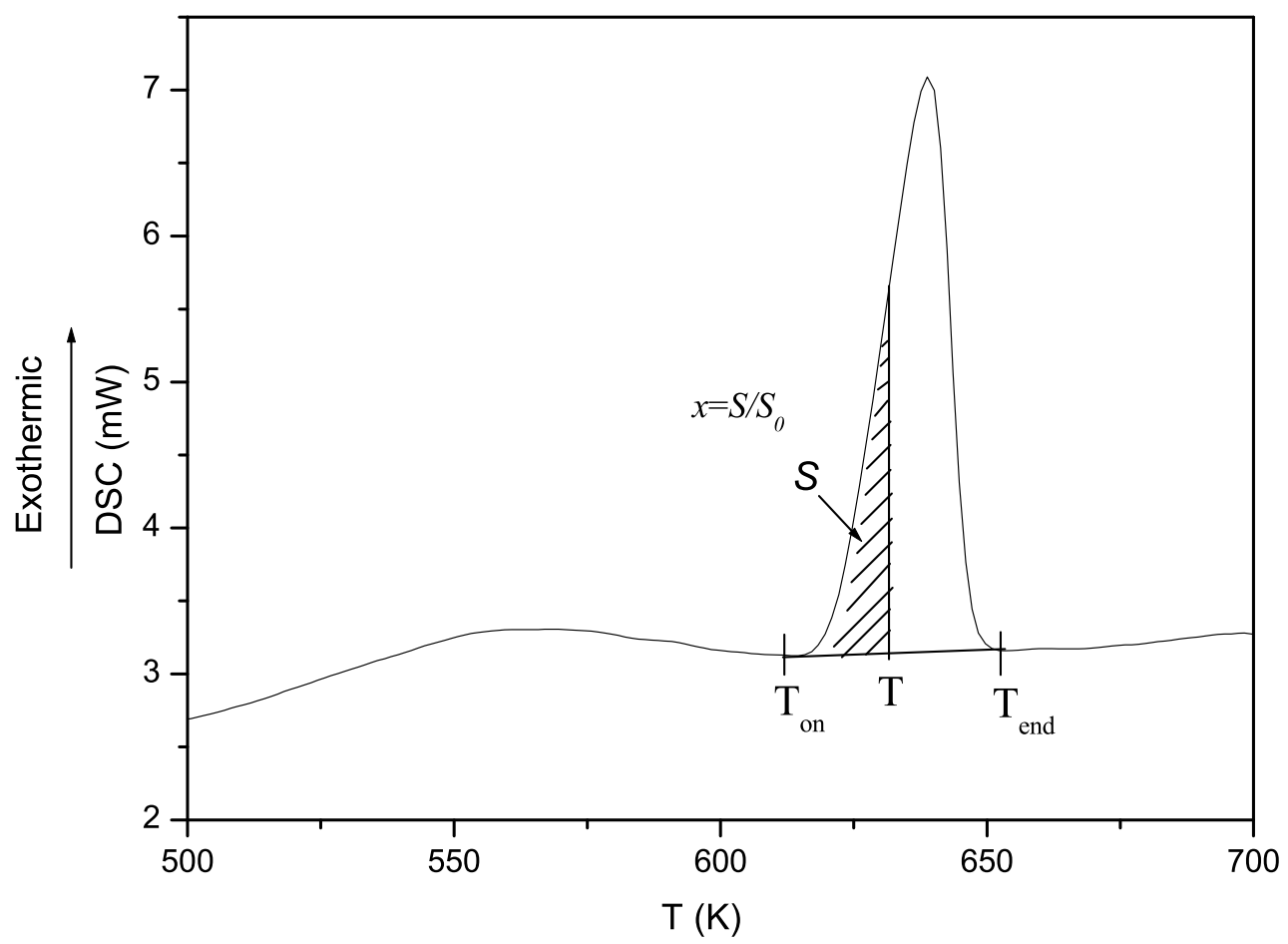

Where $S_{0}$ is the total area under the crystallization curve i.e. the area under the curve between the temperature at the onset of crystallization $T_{\text {on }}$ and the end-set temperature $T_{\text {end }}$ when the crystallization is completed. $S$ is the area at any temperature $\mathrm{T}$ between $\mathrm{T}_{\mathrm{on}}$ and $\mathrm{T}$ at which the fractional crystallization is required to be known.

There are three important modes of crystallization involving nucleation and growth processes, depending on the composition of a particular alloy: primary crystallization, polymorphous 
crystallization and eutectic crystallization (Hsiao et al., 2002). In primary crystallization the primary phase of the alloy constituents crystallizes first. The dispersed primary crystallized phase coexists with the amorphous matrix and may serve as the nucleation site for secondary or tertiary crystallization. In Fe-based alloys a-Fe crystallizes first, which is a kind of primary crystallization. Polymorphous crystallization is a transition of the amorphous phase to a crystalline one without any change in the composition of that phase. There is no concentration difference across the reaction front because the concentration does not change. Eutectic crystallization is simultaneous crystallization of two crystalline phases by a discontinuous reaction. This reaction takes longer than polymorphous crystallization to proceed because the two components have to separate by diffusion into two separate phases within the crystallized region (Minic, 2006).

\section{Results and discussion}

The DSC thermograms at four different heating rates are shown in Fig.1. The thermograms show three-stage crystallization. The first crystallization peak is evaluated for heating rates 4, 6, 8 and $10 \mathrm{deg} / \mathrm{min}$. Glass transition becomes clear as we go for the higher heating rates, but the third crystallization peak becomes less prominent as we go to the higher heating rates. The onset and endset of first crystallization exotherms exhibit different levels of heat flow i.e. the crystallization ends at slightly higher level followed by the second and third crystallization peak. This difference of the level indicates that the phases at the start of crystallization and at the end of it are not same. The analysis of DSC data to evaluate the kinetic parameters can be obtained from non-isothermal rate laws by both isokinetic also known as model fitting methods and isoconversional methods.

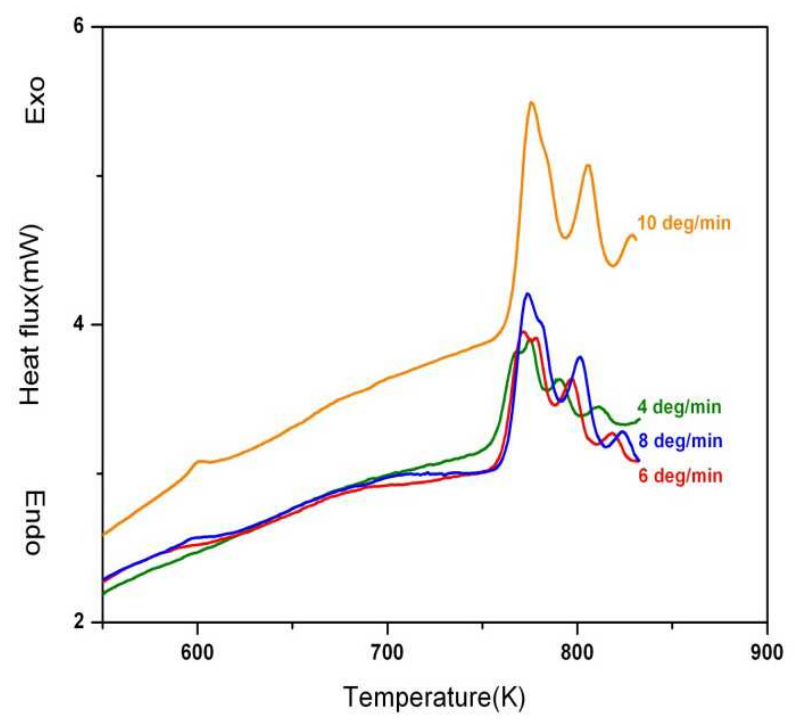

Fig. 1. DSC thermograms of the metallic glass $\mathrm{Co}_{66} \mathrm{Si}_{12} \mathrm{~B}_{16} \mathrm{Fe}_{4} \mathrm{Mo}_{2}$ at different heating rates 


\subsection{Isoconversional analysis}

The isoconversional methods require the knowledge of temperatures $T_{\alpha}(\beta)$ at which an equivalent stage of reaction occurs for various heating rates. The equivalent stage is defined as the stage at which a fixed amount is transformed or at which a fixed fraction, $\alpha$ of the total amount is transformed (Starink, 1997). These methods are further categorized as linear and non-linear isoconversional methods. The linear integral isoconversional methods (Kissinger, 1957; Ozawa, 1965; Augis \& Bennett, 1978; Boswell, 1980; Flynn \& Wall, 1966; Akahira \& Sunose, 1971; Li \& Tang, 1999) depend on the approximation of the temperature integral and require the data on $T_{\alpha}(\beta)$. The differential isoconversional methods depend on the rate of transformation at $T_{\alpha}(\beta)$ and the data on $T_{\alpha}(\beta)$ (Gupta et al., 1988; Friedman, 1964; Gao \& Wang, 1986). Vyazovkin (Vyazovkin \& Wight, 1997) introduced a non-linear isoconversional method to increase the accuracy of evaluating the activation energy. The isoconversional methods are based on the basic kinetic equation (Paulik, 1995)

$$
\frac{d \alpha}{d T}=\frac{1}{\beta} k(T) f(\alpha)=\frac{A}{\beta} \exp \left(-\frac{E}{R T}\right) f(\alpha)
$$

where $k(T)$ is the rate constant, $\beta$ is the heating rate, $\alpha$ is the conversion fraction and $f(\alpha)$ is the reaction model which in case of KJMA formalism gives the Eq. (1). Eq. (3) can also be expressed in the integral form as

$$
g(\alpha)=\int_{0}^{\alpha}[f(\alpha)]^{-1} d \alpha=\frac{A}{\beta} \int_{0}^{T} \exp \left(-\frac{E}{R T}\right) d T
$$

As mentioned earlier, exact solution of the temperature integral is not available and various approximations made for this has resulted into different methods. We have selected a few most commonly used methods. The accuracy of various isoconversional methods and, the experimental and analytical errors associated with these methods are discussed in detail by Starink (Starink, 2003). Roura and Farjas (Roura \& Farjas, 2009) have proposed an analytical solution for the Kissinger equation. Rotaru and Gosa (Rotaru \& Gosa, 2009) describe their recently developed software that implements a number of known techniques such as various isoconversional methods, a method of invariant kinetic parameters, master plots methods, etc. Cai and Chen (Cai \& Chen, 2009) have proposed a new numerical routine for a linear integral isoconversional method that allows one to obtain accurate values of the activation energy in the cases when the latter varies strongly with the extent of conversion. Criado et al. (Criado et al., 2008) provide a critical overview of isoconversional methods, putting the focus on establishing whether the observed variations in the activation energy are real or apparent (Vyazovkin, 2010).

\section{Linear integral isoconversional methods}

a. Ozawa-Flynn-Wall (OFW) method

In this method (Ozawa, 1965; Augis \& Bennett, 1978; Boswell, 1980; Flynn \& Wall, 1966) the temperature integral in Eq. (4) is simplified by using the Doyle's approximation (Doyle, $1961,1962,1965)$ and hence we obtain the following equation: 


$$
\ln \beta=-1.0516 \frac{E(\alpha)}{R T_{\alpha}}+\text { const }
$$

The plot of $\ln \beta$ vs 1000/Ta (Fig.2) gives the slope $-1.0516 E(a) / R$ from which the activation energy has been evaluated (Table 1). At $T_{\alpha}=T_{p}$ (Ozawa method) the value of $E$ determined using Eq. (5) is given in Table 2.

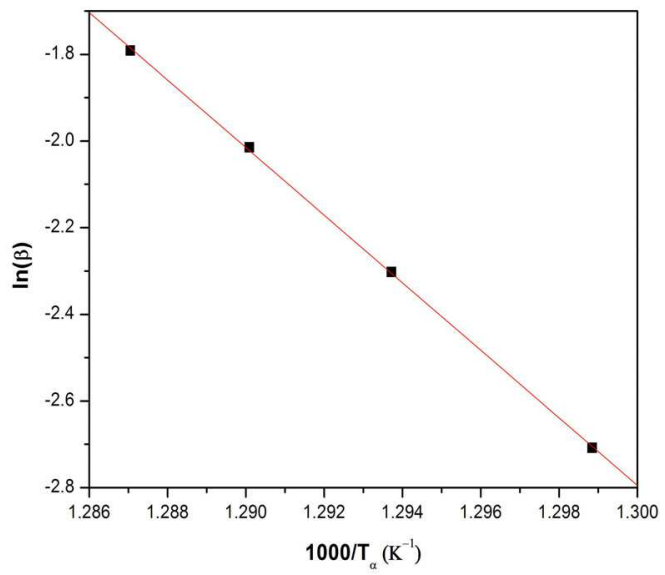

Fig. 2. OFW plot for peak-1

b. Kissinger-Akahira-Sunose (KAS) method

Kissinger, Akahira and Sunose (Kissinger, 1957; Ozawa, 1965; Augis \& Bennett, 1978; Boswell, 1980; Flynn \& Wall, 1966; Akahira \& Sunose, 1971) used the approximation given by Coats \& Redfern (Coats \& Redfern, 1964) to evaluate the integral in the rate Eq. (4). KAS method is based on the expression

$$
\ln \left(\frac{\beta}{T^{2}}\right)=\ln \left(\frac{A R}{E g(\alpha)}\right)-\frac{E}{R T}
$$

The activation energy can be evaluated from the slope of plot $\ln \left(\beta / T^{2}\right)$ vs $1000 / T$ for constant conversion, a (Fig. 3) Values of $E$ are given in Table 1. The discussion given ahead describes some of the methods available in the literature which are basically special cases of the KAS equation (6).

i) Kissinger method: This well-known method assumes that the reaction rate is maximum at the peak temperature $\left(T_{p}\right)$. This assumption also implies a constant degree of conversion $(\alpha)$ at $T_{p}$. The equation used by Kissinger is

$$
\ln \left(\frac{\beta}{T_{p}^{2}}\right)=-\frac{E}{R T_{p}}+\ln \left(\frac{A R}{E}\right)
$$

A plot of $\ln \left(\beta / T_{p^{2}}\right)$ vs $1000 / T_{p}$ gives an approximate straight line and the activation energy $E$ is calculated using the slope (Table 2). 


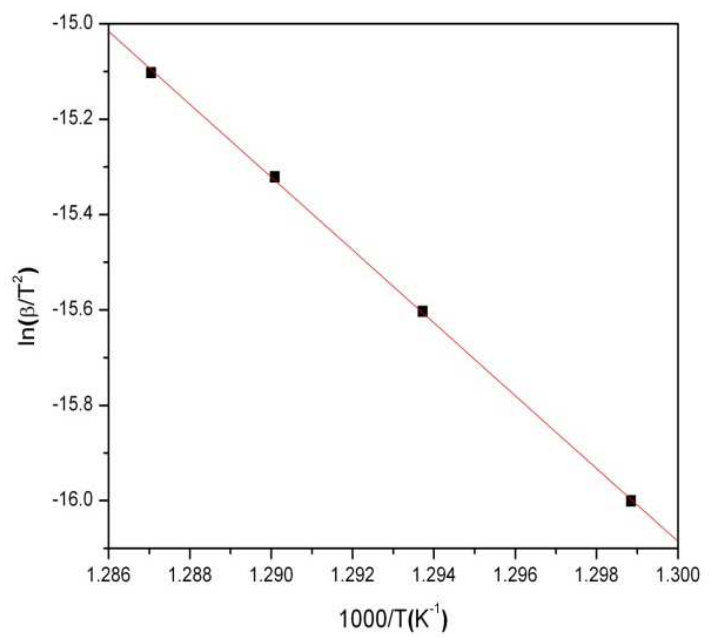

Fig. 3. KAS plot for peak-1

ii) Augis \& Bennett's method: This method was suggested by Augis and Bennett (Augis \& Bennett, 1978) and is an extension of Kissinger method showing its applicability to heterogeneous reaction described by Avrami expression. Apart from the peak crystallization temperature it also incorporates the onset temperature of crystallization, $T_{0}$ and it is supposed to be a very accurate method of determining $E$ through the equation

$$
\ln \left(\frac{\beta}{\left(T_{p}-T_{o}\right)}\right)=-\frac{E}{R T_{p}}+\ln A
$$

where $T_{p}$ and $T_{o}$ are the peak and the onset temperatures of crystallization respectively. The values of $E$ obtained from the plot $\left(\ln \left(\beta /\left(T_{p}-T_{o}\right)\right)\right.$ vs $1000 / T_{p}$ is given in Table 2 .

Further,

$$
n=2.5 \frac{T_{p}^{2}}{\Delta T\left(\frac{E}{R}\right)}
$$

where $\Delta \mathrm{T}$ is the full width at half maximum of the DSC curve. $n$ can be derived using Eq. (9). iii) Boswell method: Boswell (Boswell, 1980) has found a limitation in the Augis \& Bennett method that if

$$
\frac{T_{p}-T_{o}}{T_{p}} \approx 1
$$

then Augis \& Bennett gives crude results. However, it may be noted that this condition may not apply to the present case. 
Boswell method determines the activation energy at peak temperature (Table 2) using the following equation

$$
\ln \left(\frac{\beta}{T_{p}}\right)=-\frac{E}{R T_{p}}+\text { const }
$$

c. Li-Tang Method

Li and Tang (Li \& Tang, 1999) have developed an isoconversional integral method which does not make any assumption about the kinetic model and involves no approximation in the Eq. (3) as

$$
\int_{0}^{\alpha}\left(\ln \frac{d \alpha}{d t}\right) d \alpha=G(\alpha)-\frac{E_{\alpha}}{R} \int_{0}^{\alpha}\left(\frac{1}{T}\right) d \alpha
$$

Where $G(\alpha)=\alpha \ln A+\int_{0}^{\alpha}(\ln f(\alpha)) d \alpha$ has the same value for a given reaction under study and a given $\alpha$ irrespective of $\beta$. A plot of $\int_{0}^{\alpha} \ln \left(\frac{d \alpha}{d t}\right) d \alpha$ vs $\int_{0}^{\alpha}\left(\frac{1}{T}\right) d \alpha$, for a set of $\beta$ s at constant conversion $\alpha$ will have the slope $-E / R$.

\section{Linear differential isoconversional method}

The method suggested by Friedman (Friedman, 1964) sometimes known as transformation rate-isoconversional method, utilizes the differential of the transformed fraction and hence it is called differential isoconversional method. Substituting value of $k(T)$ in Eq. (3) and taking logarithm, Friedman derived a linear differential isoconversional expression as

$$
\ln \left(\frac{d \alpha}{d t}\right)_{\alpha}=\ln \beta\left(\frac{d \alpha}{d T}\right)_{\alpha}=\ln (A f(\alpha))-\frac{E_{\alpha}}{R T_{\alpha}}
$$

by taking logarithm on both sides of Eq.(3). For a constant $\alpha$, the plot of $\ln \left(\beta \frac{d \alpha}{d T}\right) v s\left(\frac{1}{T}\right)$ should be a straight line (Fig. 4) whose slope gives us the value of $E$ (Table 1).

Since this method does not take any mathematical approximation for the temperature integral, it is considered to give accurate estimate of $E$. Thus the method does not require any assumption on $f(\alpha)$, i.e. it is a so-called model-free method. However, being a differential method, its accuracy is limited by the signal noise (Dhurandhar et al, 2010).

A method suggested by Gao and Wang (Gao \& Wang, 1986) is a special case of the Friedman method. This method uses the following expression to determine the activation energy.

$$
\ln \left(\beta \frac{d \alpha}{d T_{p}}\right)=-\frac{E}{R T_{p}}+\text { const }
$$




$$
K_{p}=\frac{\beta E}{R T_{p}^{2}}
$$

where,

$$
K_{p}=A \exp \left(\frac{-E}{R T_{p}}\right) \text { and }\left(\frac{d \alpha}{d t}\right)_{p}=0.37 n K_{p}
$$

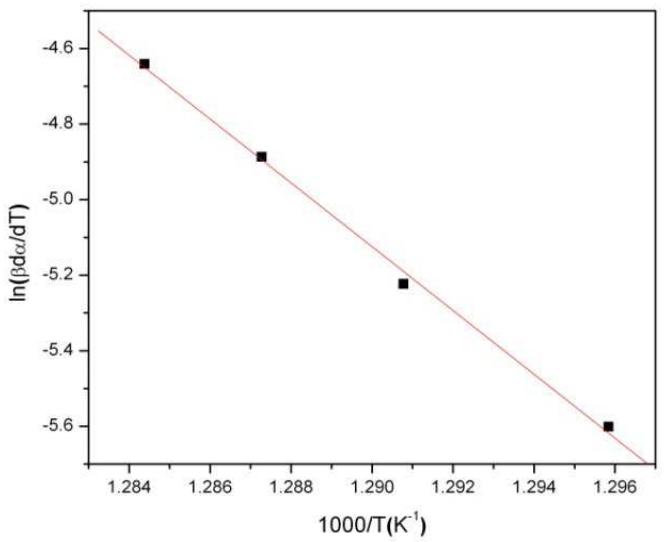

Fig. 4. Friedman plot for peak-1

\begin{tabular}{|l|c|c|c|}
\hline \multirow{2}{*}{$\alpha$} & \multicolumn{3}{|c|}{$\mathrm{E}(\mathrm{kJ} / \mathrm{mol})$} \\
\cline { 2 - 4 } & KAS & OFW & Friedman \\
\hline 0.1 & $602 \pm 2$ & $584 \pm 2$ & $555 \pm 1$ \\
\hline 0.2 & $597 \pm 1$ & $580 \pm 1$ & $626 \pm 1$ \\
\hline 0.3 & $603 \pm 1$ & $586 \pm 2$ & $648 \pm 1$ \\
\hline 0.4 & $615 \pm 1$ & $597 \pm 1$ & $687 \pm 1$ \\
\hline 0.5 & $635 \pm 1$ & $616 \pm 1$ & $725 \pm 1$ \\
\hline 0.6 & $654 \pm 1$ & $634 \pm 1$ & $702 \pm 3$ \\
\hline 0.7 & $648 \pm 1$ & $629 \pm 1$ & $522 \pm 5$ \\
\hline 0.8 & $606 \pm 1$ & $589 \pm 1$ & $398 \pm 5$ \\
\hline 0.9 & $549 \pm 1$ & $534 \pm 1$ & $318 \pm 2$ \\
\hline
\end{tabular}

Table 1. Local Activation energy (E) at different conversion for different methods.

\begin{tabular}{|l|c|}
\hline Method & $\mathrm{E}(\mathrm{kJ} / \mathrm{mol})$ \\
\hline Kissinger & $553 \pm 2$ \\
\hline Ozawa & $546 \pm 2$ \\
\hline Augis \& Bennett & $532 \pm 2$ \\
\hline Boswell & $443 \pm 7$ \\
\hline
\end{tabular}

Table 2. Activation energy (E) using various methods. 


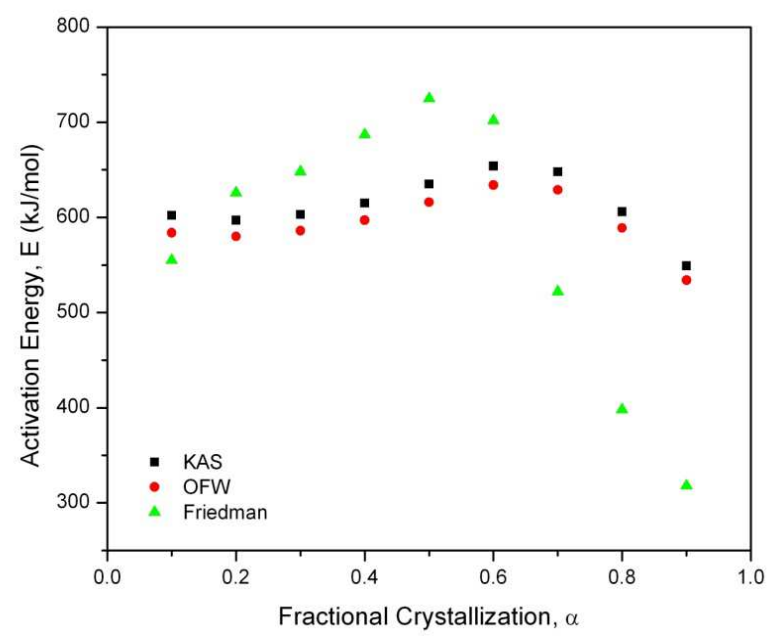

Fig. 5. Local Activation energy E at different $\alpha$ from different methods

\section{Non-linear isoconversional method}

Vyazovkin and Wight (Vyazovkin \& Wight, 1997) described an advanced isoconversional method. Similar to other isoconversional methods, this method is also based on the assumption that the reaction model, $g(\alpha)$ is independent of the heating program. So, for any two experiments conducted at different heating rates the ratio of the temperature integral I $\left(\mathrm{E}, \mathrm{T}_{\alpha}\right)$ to the heating rate $\beta$ is a constant. For a given conversion and a set of $\mathrm{n}$ experiments performed under different heating rates, the activation energy can be determined at any particular value of $\alpha$ by finding the value of $E_{\alpha}$ for which the function

$$
\sum_{i \neq j}^{n} \sum^{n} \frac{\left[I\left(E_{\alpha}, T_{\alpha i}\right) \beta_{j}\right]}{\left[I\left(E_{\alpha}, T_{\alpha j}\right) \beta_{i}\right]}
$$

is a minimum. The minimization procedure is repeated for each value of $\alpha$ to find the dependence of activation energy on the extent of conversion.

\subsection{Isokinetic methods}

a. Matusita and Sakka method

Matusita and Sakkka (Matusita \& Sakka, 1979) suggested the following equation specifically for the non-isothermal data

$$
\ln [-\ln (1-\alpha)]=-n \ln \beta-\frac{m E}{R T}+\text { Const }
$$

where $m$ is an integer depends on the dimensionality of the crystal and the Avarami exponent $n$ depends on the nucleation process. For a constant temperature, the plot of $\ln [-$ 
$\ln (1-\alpha)]$ versus $\ln \beta$ gives a straight line (Fig.6) and the slope gives the value of $n$, which come out to be $n=1.33$ and $n=1.36$ for temperatures $\mathrm{T}=775 \mathrm{~K}$ and $T=778 \mathrm{~K}$ respectively. The plot of $\ln [-\ln (1-\alpha)]$ versus $1 / \mathrm{T}$ at constant heating rate should be a straight line and the value of $\mathrm{mE}$ is obtained from the slope (Fig.7).

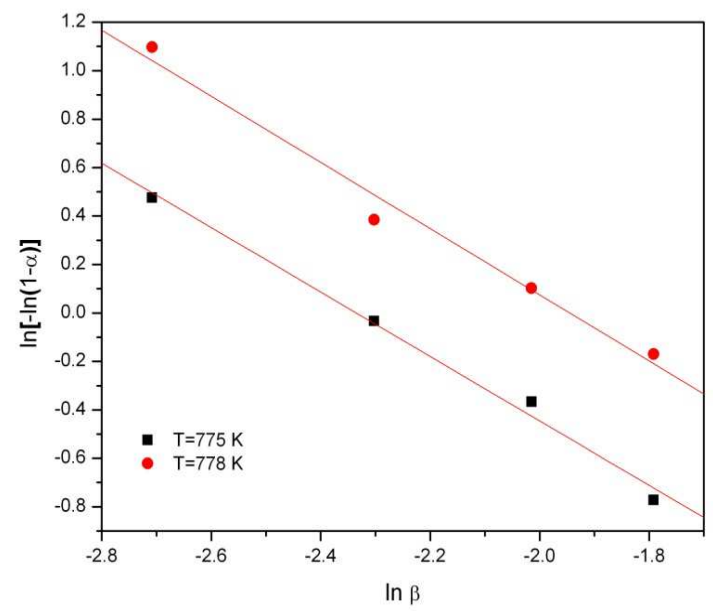

Fig. 6. Plot of $\ln [-\ln (1-\alpha)]$ Vs. $\ln \beta$ for diff. Temp.

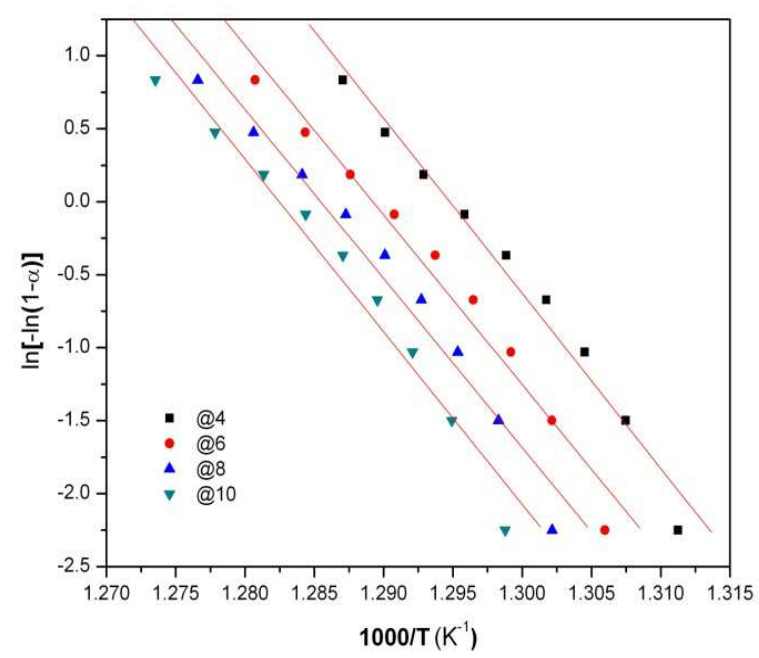

Fig. 7. Plot of $\ln [-\ln (1-\mathrm{a})]$ Vs. 1000/T for diff. heating rates.

a) Modified Kissinger method

The modified Kissinger equation (Matusita \& Sakka, 1980) given below can be utilized to derive the activation energy $(E)$. 


$$
\ln \left(\frac{\beta^{n}}{T_{p}^{2}}\right)=-\frac{m E}{R T_{p}}+\text { Const }
$$

Where $E$ is the activation energy for crystallization, $T_{p}$ is the peak temperature and $R$ is the universal gas constant. $m$ is known as the dimensionality of growth and here $m=n$. In order to derive $E$ from this equation, one must know the value of $n$. The $n$ value can be obtained from the slope of the plot of $\ln [-\ln (1-\alpha)]$ Vs. $\ln \beta$ at constant temperature. In order to evaluate $E$, the values of $n$ are substituted in Eq. (17). Then plots of $\ln \left(\frac{\beta^{n}}{T_{p}^{2}}\right)$ Vs. $\frac{1}{T_{p}}$ (Fig. 8) gives the values of activation energy $E$, and the average $E$ obtained is $549.80 \mathrm{~kJ} / \mathrm{mol}$.

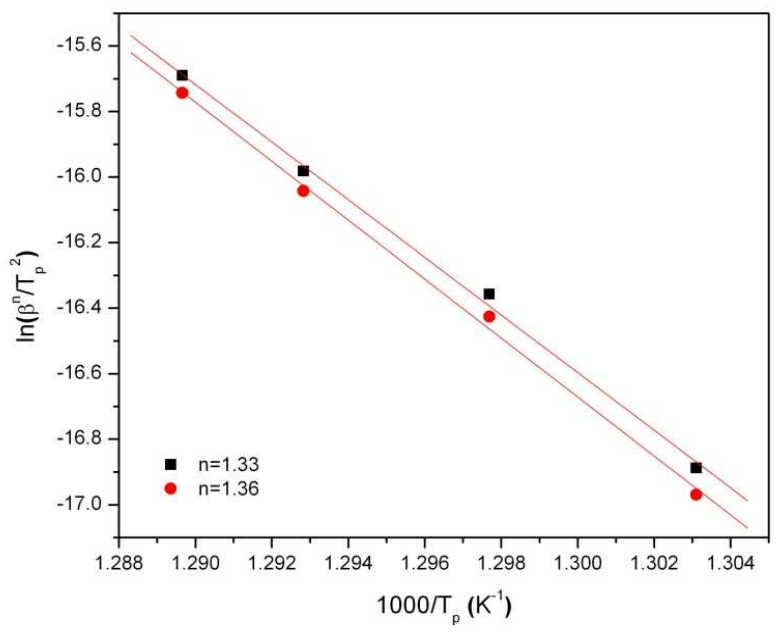

Fig. 8. Mod. Kissinger plot for $n=1.33$ and $n=1.36$

A general trend of decrease in the values of $n$ with increasing heating rate can be observed. Such trend has been also seen by Matusita and Sakka (Matusita \& Sakka, 1979) and in other Fe-based (Raval et al., 2005) metallic glasses.

\begin{tabular}{|l|l|}
\hline Heating rate & Matusita E Sakka \\
\hline 4 & 1.81 \\
\hline 6 & 1.76 \\
\hline 8 & 1.75 \\
\hline 10 & 1.79 \\
\hline
\end{tabular}

Table 3. Values of Avrami exponent (n) 
b. Coats \& Redfern method

One of the most popular model-fitting methods is the Coats and Redfern method (Coats \& Redfern, 1964). This method is based on the equation

$$
\begin{aligned}
& \ln \frac{g_{i}(\alpha)}{T^{2}}=\ln \left[\frac{A_{i} R}{\beta E_{i}}\left(1-\frac{2 R T}{E_{i}}\right)\right]-\frac{E_{i}}{R T} \\
& \cong \ln \frac{A_{i} R}{\beta E_{i}}-\frac{E_{i}}{R T}
\end{aligned}
$$

The graph of $\ln \frac{g_{i}(\alpha)}{T^{2}}$ Vs. $\frac{1}{T}$ gives a straight line whose slope and intercept allow us to calculate $E$ and $A$ for a particular reaction model. For the different kinetic models and for $0.1 \leq \alpha \leq 0.9$, the straight lines corresponding to CR method are characterized by correlation coefficients (r). The general practice in this method to determine $E$ is to look for the model corresponding to maximum $\mathrm{r}$. In some cases, the so-obtained value of $E$ is significantly different from those obtained from other methods.

c. The invariant kinetic parameter (IKP) method

It has been observed that the same experimental curve $\alpha=\alpha(T)$ can be described by different function of conversion $(f(\alpha))$. Further, the values of the activation energy obtained for various $f(\alpha)$ for single non-isothermal curve are correlated through the compensation effect (Galwey, 2003). These observations form the basis of the IKP method. In order to apply this method, $\alpha=\alpha(T)$ curves are obtained at different heating rates $\left(\beta_{v}=4,6,8,10\right)$ using DSC. For each heating rate the pairs $\left(A_{v j}, E_{v j}\right)$, where $j$ corresponds to a particular degree of conversion, are determined using the following equation:

$$
\ln \frac{g(\alpha)}{T^{2}}=\ln \frac{A R}{\beta E}-\frac{E}{R T}
$$

For constant $\beta$, a plot of $\ln \frac{g(\alpha)}{T^{2}}$ Vs. $\frac{1}{T}$ is a straight line whose slope allows the evaluation of activation energy $E_{v}$ and intercept, pre-exponential factor, $A_{v}$ for different reaction models $g(\alpha)$. The same procedure is repeated to obtain the pairs $\left(E_{v} A_{v}\right)$ for different heating rates. Now, the calculation of invariant activation parameters is done using the compensation relation (Budrugeac, 2007)

$$
\ln A_{v}=\alpha^{*}+\beta^{*} E_{v}
$$

The Eq. (20) represents a linear relationship between $\ln A$ and $E$; any increase in the magnitude of one parameter is offset, or compensated, by appropriate increase of the other. Plotting $\ln A_{v}$ Vs. $E_{v}$ for different heating rates, the compensation effect parameters $\alpha^{*}$ and $\beta^{*}$ are obtained. These parameters follow an equation

$$
\alpha^{*}=\ln A-\beta^{*} E
$$




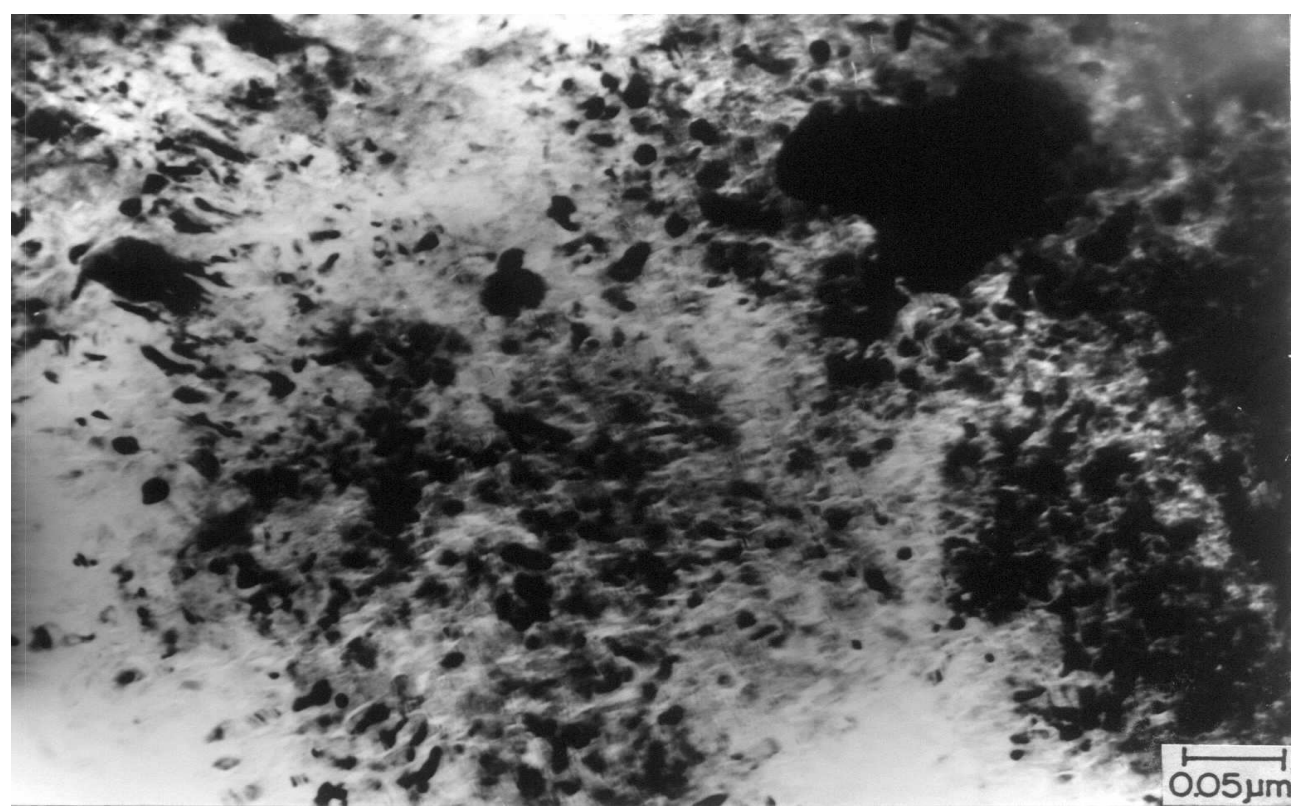

Fig. 9. Bright field TEM image of $\mathrm{Ti}_{20} \mathrm{Zr}_{20} \mathrm{Cu}_{60}$ metallic glass after annealing at $673 \mathrm{~K}$ for 4 hours

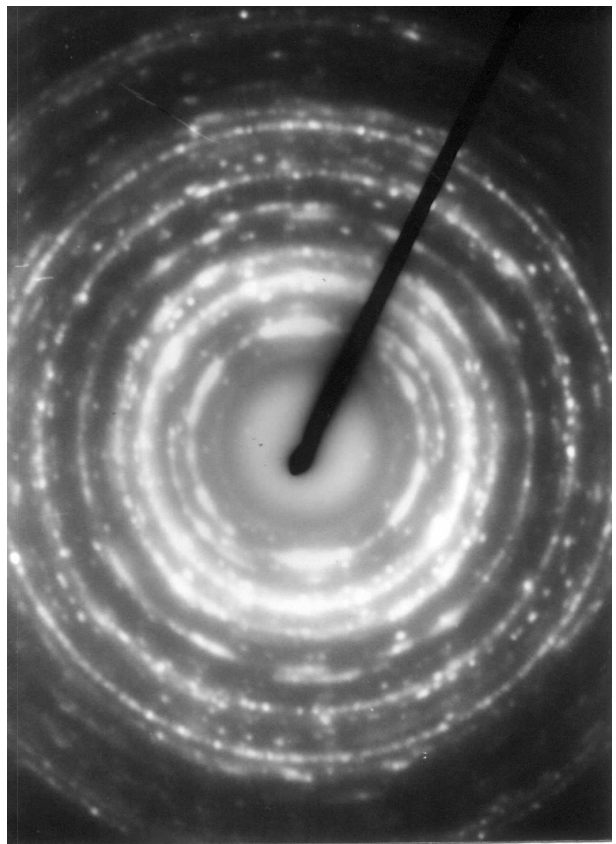

Fig. 10. SAD pattern of $\mathrm{Ti}_{20} \mathrm{Zr}_{20} \mathrm{Cu}_{60}$ metallic glass after annealing at $673 \mathrm{~K}$ for 4 hours 
The plot of $\alpha^{*}$ and $\beta^{*}$ gives the true values of $E$ and $A$.

Nano-structures can be synthesized by controlled crystallization of metallic glasses also known as de-vitrification method.

The selected area diffraction (SAD) pattern shows characteristic rings with discontinuity. The phases can also be idetified as seen from fig.11.

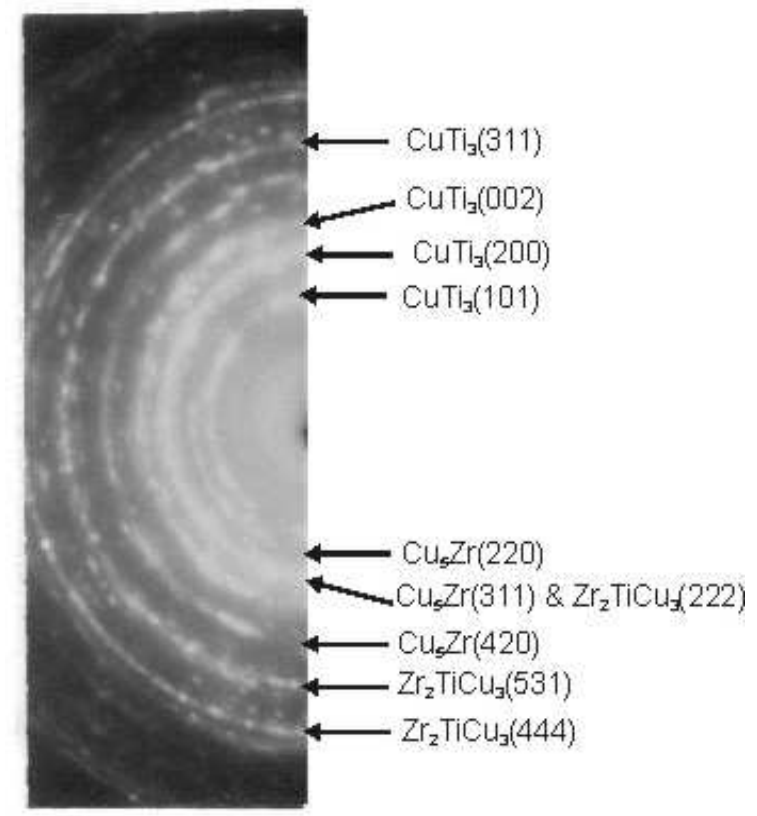

Fig. 11. Nano-phases present in $\mathrm{Ti}_{20} \mathrm{Zr}_{20} \mathrm{Cu}_{60}$ metallic glass after annealing at $673 \mathrm{~K}$ for 4 hours

\section{Conclusion}

Based on the analysis of thermo-analytical data, the very obvious and straight forward question is: which is better, iso-conversional or iso-kinetic?

Iso-conversional methods provide activation energy values, $E$ as a function of conversion, $\alpha$. The iso-kinetic methods, on the other hand, are used considering the crystallization mechanism to be the same throughout the entire conversion (crystallization) and give single constant value of activation energy. For metallic glasses, the thermally activated phase transformations are more physical than chemical. In fact, crystallization is a complex process involving nucleation and growth and on rigorous grounds, it can not be considered to be a single-step process. The iso-kinetic analysis always leads to a single activation energy (rather say, apparent activation energy) giving an overall picture of the crystallization process. However, the difficulty (and hence uncertainty) in choosing the proper reaction model persists in isokinetic analysis. Therefore, the isoconversional methods are definitely 
superior to the isokinetic methods as far as the determination of $E$ is concerned (Pratap et al, 2007). Nonetheless, accurate determination of $E$ is not the only issue in the kinetic analysis of crystallization process in metallic glasses. The micro-structural evolution during the nonisothermal heating of the metallic glasses is also important. For the determination of the dimensionality of the growth and the grain size, one needs to know a precise reaction model that closely follows the crystallization process. A reaction model independently proposed by John-Mehl- Avrami-Kolmogorov (JMAK) is found to be the most suitable for describing the nucleation and growth process during the non- isothermal crystallization of metallic glasses. This model does help to determine of the kinetic parameters, like the dimensionality of growth (apart from $E$ and $A$ ). The model-free isoconversional methods are definitely superior to the isokinetic methods for the accurate determination of kinetic parameters like $\mathrm{E}$ and $\mathrm{A}$. However, the knowledge of accurate $\mathrm{E}$ and $\mathrm{A}$ is not sufficient for the detailed investigations of the dimensionality of the growth and the grain size using thermal analysis. A precise reaction model accounting for the phase transformations during the crystallization process is a prerequisite for deriving such micro-structural information. This could be a valid proposition if it is explicitly related to the phase transformations involving significant chemical changes. One can find numerous publications where JMAK formalism has been found to be the most appropriate for the description of kinetics of nucleation and growth processes in metallic glasses. Therefore, in our opinion, isokinetic methods (despite its limited applicability) are important and useful for the analysis of non-isothermal crystallization data. So, as far as the study of thermally activated phase transformation in metallic glasses is concerned, both the types of methods are complementary and provide not only useful data, but also pave way into the insight of the crystallization process.

\section{References}

Afify, S. (1991). Differential scanning calorimetric study of chalcogenide glass $\mathrm{Se}_{0.7} \mathrm{Te}_{0.3}$, Journal of Non Crystalline Solids, Vol. 128, pp. 279-284; ISSN: 0022-3093

Akahira, T. \& Sunose, T. (1971). Joint convention of four electrical institutes, Research Report, Chiba. Institute of Technology (Science and Technology), Vol. 16, pp. 22-31

Augis, J.A. \& Bennett, J.E. (1978). Calculation of the Avrami parameters for heterogeneous solid state reactions using a modification of the Kissinger method, Journal of Thermal Analysis and Calorimetry, Vol. 13, pp. 283-292; ISSN:1388-6150 (Print), 1572894 (electronic version)

Boswell, P.G. (1980). On the calculation of activation energies using modified Kissinger method, Journal of Thermal Analysis and Calorimetry, Vol. 18, pp. 353-358 ISSN:13886150 (Print), 1572-894 (electronic version)

Budrugeac, P. (2007). The Kissinger law and the IKP method for evaluating the nonisothermal kinetic parameters, Journal of Thermal Analysis and Calorimetry, Vol. 89, pp. 143-151 ISSN:1388-6150 (Print), 1572-894 (electronic version)

Cai, J.M. \& Chen, S.Y. (2009).A new iterative linear integral isoconversional method for the determination of the activation energy varying with the conversion degree Journal of Computational Chemistry, Vol. 30, pp. 1986-1991; Online ISSN: 1096-987X

Castro, M. (2003). Phae-field approach to heterogeneous nucleation, Physical Review B, Vol. 67, pp. 035412-035419; ISSN: 0163-1829 (Print), 1095-3795 (electronic version) 
Coats, A.W. \& Redfern J.P. (1964). Kinetic Parameters from Thermogravimetric Data, Nature (London), Vol. 201, pp. 68-69; ISSN: 0028-0836 (Print), EISSN: 1476-4687

Criado, J.M.; Sanchez-Jimenez, P.E. \& Perez-Maqueda, L.A. (2008). Journal of Thermal Analysis and Calorimetry, Vol. 92, pp. 199-203; ISSN:1388-6150 (Print), 1572-894 (electronic version)

Dhurandhar, H.; Patel, A.T.; Shanker-Rao, T.L.; Lad, K.N. \& Pratap, A. (2010). Kinetics of crystallization of Co-based multi-component amorphous alloy, Journal of ASTM International, Vol. 7, pp. 1-15; 978-0-8031-7516-7

Doyle, C.D. (1961). Kinetic Analysis of Thermogravimetric Data, Journal of Applied Polymer Science, Vol. 5, pp. 285-292; ISSN: 1097-4628

Doyle, C.D. (1962). Estimating Isothermal Life from Thermogravimetric Data, Journal of Applied Polymer Science, Vol. 6, pp. 693-642; ISSN:1097-4628

Doyle, C.D. (1965). Series Approximations to the Equation of Thermogravimetric Data, Nature (London), Vol. 207, pp. 290-291; ISSN: 0028-0836 (Print), EISSN: 1476-4687

Flynn, J.H. \& Wall, L.A. (1966). General Treatment of the Thermogravimetry of Polymers, Journal of Research of the National Bureau of Standards. Section- A. Physics and Chemistry, Vol. 70A, pp. 487-523; 0022-4332

Friedman, H.L. (1964). Kinetics of thermal degradation of char-forming plastics from thermogravimetry. Application to phenolic plastic, Journal of Polymer Science Part C, Vol. 6, pp. 183-195; ISSN: 0449-2994

Galwey, A.K. (2003). Eradicating erroneous Arrhenius arithmetic, Thermochimica Acta, Vol. 399, pp. 1-29; ISSN: 0040-6031

Gao, Y.Q. \& Wang, W. (1986). On the activation energy of crystallization in metallic glasses, Journal of Non-Crystalline Solids, Vol. 81, pp. 129-134; ISSN: 0022-3093

Giridhar, A. \& Mahadevan, S. (1982). Studies on the As-Sb-Se glass system, Journal of Non Crystalline Solids, Vol. 51, pp. 305-315; ISSN: 0022-3093

Gupta, A.K.; Jena, A.K. \& Chaturvedi, M.C. (1988). A differential technique for the determination of the activation energy of precipitation reactions from Differential Scanning Calorimetric data, Scripta Metallurgica, Vol. 22, pp. 369-371; ISSN: 00369748

Hsiao, A.; McHenry, M.E.; Luaghlin, D.E.; Kramer, M.J.; Ashe, C. \& Ohkubo, T. (2002). The Thermal, Magnetic, and Structural Characterization of the Crystallization Kinetics of $\mathrm{Fe}_{88} \mathrm{Zr}_{7} \mathrm{~B}_{4} \mathrm{Cu}_{1}$, An Amorphous Soft Magnetic Ribbon, IEEE Transactions on Magnetics, Vol. 38, No. 5, pp. 3039-3044; ISSN:0018-9464

Jones, G.A.; Bonnett, P. \& Parker, S.F.H. (1986). Crystallilzation kinetics of the amorphous magnetic material 2605 Co $\left(\mathrm{Fe}_{67} \mathrm{Co}_{18} \mathrm{~B}_{14} \mathrm{Si}_{1}\right)$, Journal of Magnetism \& Magnetic Materials, Vol. 58, pp. 216-226; ISSN:0304-8843

Kissinger, H.E. (1957). Reaction kinetics in differential thermal analysis, Analytical Chemistry, Vol. 29, pp. 1702-1706; ISSN:0003-2700

Lad, K.N.; Savalia, R.T.; Pratap, A., Dey, G.K. \& Banerjee, S. (2008). Isokinetic and isoconversional study of crystallization kinetics of a $\mathrm{Zr}$-based metallic glass, Thermochimica Acta, Vol. 473, pp. 74-80; ISSN: 0040-6031

Lesz, S. \& Szewieczek, D. (2005). Proceedings of the Worldwide Congress on Materials and Manufacturing Engineering and Technology COMMENT'2005, Poland, Gliwice-Wisla (CD-ROM), Vol. 637, May 16-19, 2005 
Li, C.R. \& Tang, T.B. (1999). A new method for analyzing non-isothermal thermoanalytical data from solid-state reactions, Thermochimica Acta, Vol. 325, pp. 43-46; ISSN:00406031

Ligero, R.A.; Vazquez, J.; Villares, P. \& Jimenez-Garay, R. (1990). Crystallization kinetics in the As-Se-Te system, Thermochimica Acta, Vol. 162, pp. 427-434; ISSN: 0040-6031

Matusita, K. \& Sakka, S. (1979). Kinetic study of crystallization of glass by differential scanning calorimetry, Physical Chemistry of Glasses, Vol. 20, pp. 81-84; 0031-9090

Matusita, K. \& Sakka, S. (1980). Kinetic study on Crystallization of glass by differential thermal analysis - criterion on application of Kissinger plot, Journal of NonCrystlline Solids, Vol. 38-39, pp. 741-746; ISSN: 0022-3093

Minic D.M. (2006). Synthesis, Characterization and Stability of Amorphous Alloys, Science of Sintering, Vol. 38, pp. 83-92; 0350-820x

Minic, D.M. \& Adnadevic, B. (2008). Mechanism and kinetics of crystallization of a-Fe in amorphous $\mathrm{Fe}_{81} \mathrm{~B}_{13} \mathrm{Si}_{4} \mathrm{C}_{2}$ alloy, Thermochimica Acta., Vol. 474, pp. 41-46; ISSN: 00406031

Minic, D.M.; Gavrilovic, A.; Angerer, P.; Minic, D.G. \& Mariclc, A. (2009). Thermal stability and crystallization of $\mathrm{Fe}_{89.8} \mathrm{Ni}_{1.5} \mathrm{Si}_{5.2} \mathrm{~B}_{3} \mathrm{C}_{0.5}$ amorphous alloy, Journal of Alloys and Compound, Vol. 482, pp. 502-507; ISSN: 0925-8388

Moharram, A.H.; El-Oyoun, M.A. \& Abu-Sehly, A.A. (2001). Calorimetric study of the chalcogenide $\mathrm{Se}_{72.5} \mathrm{Te}_{20} \mathrm{Sb}_{7.5}$ glass, Journal of Physics D Applied Physics, Vol. 34, pp. 2541-2546; ISSN 0022-3727 (Print) ISSN 1361-6463 (Online)

Ozawa, T. (1965). A New Method of Analyzing Thermogravimetric Data, Bulletin of the Chemical Society of Japan, Vol. 38, pp. 1881-1886; ISSN 0009-2673

Patel, A.T. \& Pratap, A. (2012). Kinetics of crystallization of $\mathrm{Zr}_{52} \mathrm{Cu}_{18} \mathrm{Ni}_{14} \mathrm{Al}_{10} \mathrm{Ti}_{6}$ glass, Journal of Thermal Analysis and Calorimetry, Vol. 107, pp. 159-165; ISSN:1388-6150 (Print), 1572-894 (electronic version)

Paulik, F. (1995). Ch. 10, Special Trends in Thermal Analysis, John Wiley \& Sons, Chichester, UK

Pratap, A.; Shanker-Rao, T.L.; Lad, K.N. \& Dhurandhar, H.D. (2007). Isoconversional vs. Model fitting methods A case study of crystallization kinetics of a Fe-based metallic glass, Journal of Thermal Analysis and Calorimetry, Vol. 89, pp. 399-405; ISSN:13886150 (Print), 1572-894 (electronic version)

Raval, K.G.; Lad, K.N.; Pratap, Arun; Awasthi, A.M. \& Bhardwaj, S. (2005). Crystallization kinetics of a multicomponent Fe-based amorphous alloy using modulated differential scanning calorimetry, Thermochimica Acta, Vol. 425, pp. 47-57; ISSN: 0040-6031

Rotaru, A. \& Gosa, M. (2009). Computational thermal and kinetic analysis Complete standard procedure to evaluate the kinetic triplet form non-isothermal data, Journal of Thermal Analysis and Calorimetry, Vol. 97, pp. 421-426; ISSN:1388-6150 (Print), 1572-894 (electronic version)

Roura, P. \& Farjas, J. (2009).Analytical solution for the Kissinger equaton, Journal of Materials Research, Vol. 24, pp. 3095-3098;

Rysava, N.; Spasov, T. \& Tichy, L. (1987). Isothermal DSC methods for evaluation of the kinetics of crystallization in the Ge-Sb-S glassy system, Journal of Thermal Analysis, Vol. 32, pp. 1015-1021; ISSN:1388-6150 (Print), 1572-894 (electronic version) 
Starink, M.J. (2003). The determination of activation energy form linear heating rate Experiments: A comparison of the accuracy of isoconversion methods, Thermochimica Acta, Vol. 404, pp. 163-176; ISSN: 0040-6031

Starink, M.J. (1997). On the applicability of isoconversion methods for obtaining the activation energy of reactions within a temperature-dependent equilibrium state, Journal of Materials Science, Vol. 32, pp. 6505-6512; ISSN: 0022-2461

Szewieczek, D. \& Lesz, S. (2004). The Structure and Selected Physical Properties of the Nanocrystalline $\mathrm{Fe}_{92.4} \mathrm{Hf}_{4.2} \mathrm{~B}_{3.4}$ Alloy, Journal of Materials Processing Technology, Vol. 157-158, pp. 771-775; ISSN:0924-0136

Szewieczek, D. \& Lesz, S. (2005). Influence of Structure on Magnetic and Mechanical Properties of Amorphous and Nanocrystalline $\mathrm{Fe}_{85.4} \mathrm{Hf}_{1.4} \mathrm{~B}_{13.2}$ Alloy, Proceedings of the 13th International Scientific Conference, Achievements in Mechanical $\mathcal{E}$ Materials Engineering AMME'05, Gliwice-Wisla, Vol. 637

Vyazovkin, S. \& Wight, C.A. (1997). Isothermal and Nonisothermal Reaction Kinetics in Solids: In Search of Ways toward consensus, The Journal of Physical Chemistry A, Vol. 101, pp. 8279-8284; ISSN: 1089-5639

Vyazovkin, S. (2003). Reply to "What is meant by the term 'variable activation energy when applied in the kinetics analyses of solid state decompositions (crystolysis reactions)?", Themochimica Acta, Vol. 397, pp. 269-271; ISSN:0040-6031

Vyazovkin, S. (2010). Thermal Analysis, Analytical Chemistry, Vol. 82, pp. 4936-4949; ISSN 0003-2700 


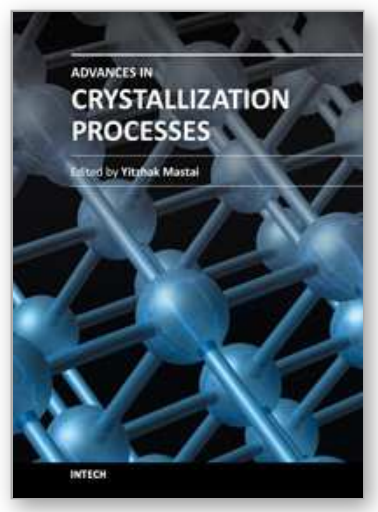

\section{Advances in Crystallization Processes}

Edited by Dr. Yitzhak Mastai

ISBN 978-953-51-0581-7

Hard cover, 648 pages

Publisher InTech

Published online 27, April, 2012

Published in print edition April, 2012

Crystallization is used at some stage in nearly all process industries as a method of production, purification or recovery of solid materials. In recent years, a number of new applications have also come to rely on crystallization processes such as the crystallization of nano and amorphous materials. The articles for this book have been contributed by the most respected researchers in this area and cover the frontier areas of research and developments in crystallization processes. Divided into five parts this book provides the latest research developments in many aspects of crystallization including: chiral crystallization, crystallization of nanomaterials and the crystallization of amorphous and glassy materials. This book is of interest to both fundamental research and also to practicing scientists and will prove invaluable to all chemical engineers and industrial chemists in the process industries as well as crystallization workers and students in industry and academia.

\section{How to reference}

In order to correctly reference this scholarly work, feel free to copy and paste the following:

Arun Pratap and Ashmi T. Patel (2012). Crystallization Kinetics of Metallic Glasses, Advances in Crystallization Processes, Dr. Yitzhak Mastai (Ed.), ISBN: 978-953-51-0581-7, InTech, Available from: http://www.intechopen.com/books/advances-in-crystallization-processes/crystallization-kinetics-of-metallicglasses

\section{INTECH}

open science | open minds

\section{InTech Europe}

University Campus STeP Ri

Slavka Krautzeka 83/A

51000 Rijeka, Croatia

Phone: +385 (51) 770447

Fax: +385 (51) 686166

www.intechopen.com

\section{InTech China}

Unit 405, Office Block, Hotel Equatorial Shanghai

No.65, Yan An Road (West), Shanghai, 200040, China

中国上海市延安西路65号上海国际贵都大饭店办公楼 405 单元

Phone: +86-21-62489820

Fax: $+86-21-62489821$ 
(C) 2012 The Author(s). Licensee IntechOpen. This is an open access article distributed under the terms of the Creative Commons Attribution 3.0 License, which permits unrestricted use, distribution, and reproduction in any medium, provided the original work is properly cited. 